\title{
ESSAYS
}

\section{Crisis in Tort Law? The Institutional Perspective}

\author{
Richard B. Stewart $\dagger$
}

I.

The tort liability and insurance system displays symptoms of potential crisis. These symptoms are most acute in the context of personal injuries caused by business, professional, and government enterprise activities. Liability insurance rates have increased sharply. In some fields, affordable insurance has not been available at all from commercial insurers. Very large jury verdicts are increasingly common. The threat of enormous tort liabilities has driven major corporations to bankruptcy. Concerns over liability exposure have led to withdrawal of vaccines and other medical products from the market. Administrative costs of the tort system in areas such as products liability, medical malpractice, and toxic torts far exceed the compensation provided the injured.

Not all observers regard these developments as particularly problematic or indicative of crisis. Some in fact view them as signs that tort law is energetically, and appropriately, deterring risky activities by pricing them at their social cost. But many more believe that there is a genuine crisis. These believers, however, are sharply divided as to the proper definition, diagnosis, and cure of the crisis. Three basic views have emerged.

One group of observers focuses on insurance. They define the crisis in terms of a lack of available and affordable insurance, which some attribute to a lack of competition in the insurance in-

$\dagger$ Byrne Professor of Administrative Law, Harvard University; Visiting Professor of Law, The University of Chicago. Richard Arnold, Richard Epstein, George Freeman, Spencer Kimball, John Langbein, Richard Posner, and Steven Shavell provided helpful comments on an earlier draft. 
dustry and others to underwriting practices that generate periodic bursts of premium increases. The favored cure is increased regulation of the insurance industry.

A second group defines the crisis in terms of sharply increased and far more unpredictable tort liabilities, which they attribute to specific tort doctrines and practices, many of which have been adopted recently by the courts. The cure is to eliminate or modify these doctrines and practices. The favored targets include: broad jury discretion in awarding compensatory and punitive damages; the failure of damage rules to take other sources of compensation into account; the spread of joint and several liability; expansive notions of product defect; vague standards of liability that require courts and juries to consider many factors and facts; the relaxation of traditional causation requirements; contingent fee practices; and abuse by counsel of the litigation process. These features, many believe, have set tort law askew by creating unpredictable and excessive liabilities, unduly high administrative costs, and capricious variations in recovery. Many states have passed laws limiting one or more of these practices, but change has been piecemeal.

A third group, which has received less public attention but has growing academic support, defines the crisis in terms of the tort system as a whole. Many courts have adopted an enterprise liability approach to tort, imposing broad liability on business enterprises for personal injuries in the belief that this will provide enterprises with appropriate incentives to reduce risk and provide victims with needed insurance against loss. Those who define the crisis in systemic terms believe that tort litigation is an institution inherently ill-suited to achieve these incentive and insurance goals. Particularistic, incremental reform of tort law procedure is accordingly fruitless.

The systemic critics believe that the social welfare goals of enterprise liability can best be achieved by scrapping the tort system in favor of one or more alternative institutions such as contract, no-fault liability (on the workers' compensation model), private first-party loss insurance, or government social insurance programs. Others would radically modify the private law tort system through measures to simplify and reduce litigation, or expand use of class action procedures, to transform private tort law into a fundamentally different "public law" system.

This essay finds great potential value in analysis of alternative institutions, but advises that we must move cautiously before adopting entirely new systems to replace tort law. Even accepting the systemic view of the crisis, it is not clear which of the sug- 
gested aiternatives will best serve the functions-compensation, deterrence, and condemnation - that are now assigned to the tort law system. A satisfactory resolution of the crisis will depend upon development of an adequate comparative analysis of various institutions-of their strengths and weaknesses in pursuing particular goals with respect to different types of injuries in different settings. The prevailing views of the tort law crisis often ignore these situational differences. Each view tends to offer a single uniform diagnosis and cure, regardless of context.

The American Law Institute's Project on Compensation and Liability for Product and Process Injuries ${ }^{1}$ proposes to remedy this oversight by emphasizing comparative analysis of different institutions' performance in advancing the goals currently assigned to the tort system. This essay describes how such an analysis could help us to determine whether there is a crisis of tort law, and to the extent such a crisis exists, its appropriate institutional diagnosis and cure. The essay's conclusions are tentative and skeptical; but in our current situation these are likely to serve better than misplaced certainty.

\section{II.}

In order to understand the systemic critique of modern tort law, one must understand the genesis of current theories of enterprise liability. At the price of severe oversimplification, it may be said that American tort law from the late nineteenth to the midtwentieth century was understood primarily in terms of corrective justice. When an actor wrongfully or without justification had injured another, the injurer was liable to make the victim whole insofar as money damages could do so. Liability redressed the moral disequilibrium caused by the defendant. In doing so, liability served three basic goals. It condemned the defendant's conduct, restored the moral equilibrium by making the victim whole through an award of damages, and deterred future wrongdoing.

In the past several decades, an enterprise theory of tort liability has emerged, carrying the banner not of corrective justice but of social welfare. The new approach has affected the conception of each of the tort system's goals.

Compensation, formerly viewed as rectification of a wrong, now is understood in terms of insurance or risk spreading. Enter-

1 For which the author is Chief Reporter. The views expressed here do not necessarily represent those of the Institute. 
prise liability theory holds an enterprise strictly liable to those injured by its activities or products (at least if the products are "defective" or lack adequate warnings) because the enterprise is in the best position to spread the risk of injury through liability insurance or self-insurance. In short, tort law has become a system of compulsory insurance that converts the risk of a large loss to a few individuals into a small surcharge borne by each consumer of the goods and services that the enterprise produces. This system assertedly reduces the costs of risk bearing and in so doing increases social welfare.

Second, enterprise liability aims to provide two sorts of incentives to reduce the risk of injury. The first and more traditional is the incentive for enterprises to take cost-effective precautions to reduce the riskiness of their activities and thereby reduce or avoid liability. The second and more novel is the incentive for enterprises to reduce their level of risky activities-an extra incentive made possible because the recent expansion of strict liability has forced enterprises to pay for the harms they cause even though they have taken cost-effective precautions. It is assumed that enterprises will add liability costs to the price of the goods and services that they produce, and that the increased price will reduce consumer demand for those goods and services. The resulting reduction in the level of an enterprise's activity will reduce the number of injuries caused.

In these respects, enterprise liability pursues two of the traditional goals of tort law while simultaneously reconceptualizing them. But it greatly attenuates the remaining goal, that of condemning traditionally blameworthy conduct-the goal that was traditionally paramount. It often imposes liability without fault, or under highly attenuated notions of fault; tort law's condemnatory function largely gives way to the principle that the enterprise's conduct, even if not blameworthy and indeed even if affirmatively desirable, must nonetheless "pay its way."

The reconceptualization of tort goals in terms of incentives and insurance has encouraged the courts to expand enterprise liability in far-reaching ways to compensate injuries caused by products, services, and pollution. Those who think that the tort law crisis stems from misguided doctrinal innovations argue that the expansion of liability has in certain respects gone too far, that it overdeters enterprises, creates excessive administrative costs, and makes insurance more expensive and more difficult to obtain. But the systemic view of the tort crisis poses a more radical critique. It holds that the present law of enterprise tort liability is at odds 
with its asserted premises, and that judicial expansion of tort liability has in important ways retarded rather than advanced the social welfare goals that supposedly justified the expansion.

For example, systematic reformers have attacked the riskspreading justification for enterprise tort liability as factually unsupportable. They have made a persuasive case that enterprises often are poorer insurers of risk than are victims, who can obtain first-party insurance, or the government, which can adopt general social insurance programs. Third-party insurance is especially costly when the risks associated with a particular enterprise (such as toxic waste disposal) are highly uncertain, or the causes of a particular injury or illness are difficult to determine. The expansion of enterprise liability has caused a shift from first-party to third-party insurance, which has doubled or tripled adminstrative costs. It may also have increased the variance of risk pools and thus adversely affected insurability. According to the systemic view, then, the reason liability insurance is costly or unavailable is the mistaken judicial assumption that enterprises are the better insurers.

The compulsory insurance aspect of enterprise products liability is also subject to attacked by the systemic critics. The compulsory insurance feature of tort law saddles all consumers with the enormous administrative costs of a third-party liability system. It also causes poorer consumers to subsidize wealthier ones. All consumers pay the same "premium," but those earning higher incomes will receive higher awards for disability. Moreover, purchasers of first-party insurance do not seek to insure against noneconomic losses; the analytics of risk bearing explain why this pattern is rational. By including noneconomic losses-such as pain and suffering-in damage awards, tort law requires consumers to purchase (through the increased price of goods and services) more insurance than they voluntarily would choose. On the other hand, inclusion of noneconomic losses in damages is appropriate from the viewpoint of incentives. Pain and suffering should be taken into account by injurers in determining appropriate levels of precaution and activity. Apparently the tort system, which makes a plaintiff's compensation equal to the defendant's liability, is unable simultaneously to provide appropriate insurance and create desirable incentives.

Third, the systemic critique also challenges the claim that existing enterprise liability provides effective incentives for both injurers and victims to avoid risk. The incentives for enterprises, the critique goes, are inadequate in some cases, especially those where 
causation is difficult to establish or liability lies far in the future; but they are excessive in other cases, particularly where liability is highly unpredictable but potentially great. According to the systemic critique, the private law of torts will never be able to create optimal, consistent incentives, because it relies on decentralized, adversarial litigation. The courts, the critics say, have further skewed incentives by disregarding the risky character of victim's conduct (for example, careless use of products) and abandoning or vitiating defenses, such as contributory negligence, misuse, and assumption of risk, that gave potential victims incentives to exercise care or reduce their own risky activities. When victims can take precautions more cheaply than can enterprises, leaving victim activity unchecked increases the costs of safety and forces careful consumers to subsidize careless ones.

Finally, the systemic reformers challenge the notion that enterprises should internalize the costs of accidents. There is no general reason, they say, to impose the costs of injury on the enterprise rather than on the potential victims. The tort system is incapable of forcing both victims and enterprises fully to internalize injury costs and reduce activity levels accordingly. Society must choose which option will maximize social welfare, and private law litigation is poorly equipped to make that determination. If it compromises the activity-level choice by splitting the loss, neither party will have an adequate incentive to take precautions.

In short, the critics of enterprise liability have turned the system's own premises against it. Tort law's new paradigm of social welfare has been turned into an indictment of tort law and a justification for abandoning the system. ${ }^{2}$

Faced with this apparent mismatch between between current law and its asserted foundations, one might turn to one of two solutions. The first solution accepts the social welfare goals of current tort law but concludes that tort litigation is inherently illsuited for achieving them. Other institutions, such as contract, pri-

2 Such reversals have occurred before in the law. For example, late nineteenth century jurists celebrated a regime of free contract on the ground that it secured individual freedom and promoted economic welfare. The Progressives used these justifications to attack freedom of contract and justify its regulation or displacement, arguing that contracts between unequals were not voluntary and that market failures required government regulation and planning to advance economic welfare. Similarly, the legal realists attacked the Langdellians' appeal to science to validate the case method of study and treatise-writing; the realists argued that the scientific method required empirical study of the legal system as it actually operates rather than conceptualist classification of appellate opinions. On the latter point, see G. E. White, Tort Law in America 59 (1980). 
vate or governmental insurance, or regulation, must take over the functions of litigation. The second solution holds that the redefinition of traditional tort goals was a mistake, and that tort liability again must be founded on principles of corrective justice. These two approaches seem very different, but surprisingly their institutional implications may be quite similar.

\section{III.}

Once the goals of tort law are recast in terms of social welfare, private tort litigation appears as only one of many possible institutions for providing compensation and insurance, creating incentives to reduce risk, and condemning socially irresponsible conduct. Choosing among these institutional solutions requires a comparative evaluation of their strengths and weaknesses in particular settings.

In fact, in some areas other institutions have already assumed much of the responsibility for achieving the social welfare goals of the tort system as a result of political judgments that they could better secure these goals. Their performance could be very instructive in evaluating the appropriateness of similar shifts in institutional responsibility as a potential response to the current "crisis." For example, tort once provided the dominant set of remedies for occupational injuries. As industrialization proceeded apace, however, workers and their families became more dependent on cash wages, and powerful new technologies generated harms that affected many persons simultaneously. The private tort litigation system could not effectively handle these new problems. It was eventually displaced or supplemented by new systems of incentives and compensation: no-fault workers' compensation liability, collective bargaining, health and safety regulation. In particular, workers' compensation, initially adopted contractually by some employers and workers and then mandated generally by legislatures, virtually eliminated tort from the field until the recent surge in products liability suits against third-party product suppliers. At the same time, new forms of individual and employment-based insurance, both government and private, arose to assume some of the compensatory function. Similar, if less sweeping, shifts have occurred in other injury settings.

Several institutions other than private tort litigation might be enlisted to deal with personal injuries caused by enterprises. They include (1) contracts and markets, including market incentives for producers to offer safer goods and services and for employers to offer safer workplaces in lieu of higher wages for riskier work, war- 
ranties and other contractual specifications of liability, and collective bargaining; (2) no-fault liability and compensation systems on the workers' compensation model; (3) regulation of hazard before injury occurs through prophylactic controls such as administrative regulation or injunctive actions, or through fees and economic incentives that make risky activities more costly; (4) government imposition, after injury occurs, of sanctions (including criminal prosecutions and civil fines) on conduct causing injury; (5) loss insurance to provide compensation to victims, purchased by individuals or provided by government.

The tort litigation system could also be radically restructured to transform it into a fundamentally different institution. One alternative is (6) a European-style litigation system designed to make litigation far less costly and protracted by eliminating juries; using specialized judges and giving them greater control over discovery, expert testimony, and trial; and requiring losing parties to pay the winners' litigation costs. Another alternative is (7) a "public law" model of tort litigation that would rely heavily on class actions, damages scheduling, and other wholesaling techniques to reduce administrative costs and make tort remedies more effective.

Any assessment of the relative merits, alone or in combination, of these alternatives to tort cannot be done in the abstract, however. Different institutions will perform differently in various contexts. One can begin by distinguishing three basic categories of personal injuries that are distinctive to enterprises, as opposed to those that are caused by individuals as well (for example, automobile injuries). There are (a) occupational injuries, (b) injuries to consumers of products and services, and (c) injuries caused by general environmental exposure to toxic substances. Depending upon the context in which an injury occurs, different circumstances will surround it, with different institutional implications.

For example, the specific cause of some injuries, including most accidents and some acute illnesses, can readily be determined, while that of many occupational or environmental illnesses cannot. The possibility and usefulness of caretaking by potential victims also vary; a victim's carefulness will not reduce the risk of injury from surgery or from general exposure to toxic pollutants, although it may reduce occupational and product-related dangers. Likewise, purchasers of consumer products know about many of the risks they face, while buyers of prescription drugs often may not. In some contexts, such as workplaces and hospitals, the enterprise exercises considerable control over the interaction between potential victims and sources of risk, while enterprises have little 
control over the victim's interaction with products and many environmental exposures. Where the injury is related to the workplace, products or services of the enterprise, the injured person and the enterprise often have a direct or indirect contractual relationship.

Such differences suggest that different institutional may be appropriate to deal with injuries occurring in different contexts. These several institutions and injury settings can be arrayed in a matrix that summarizes the present distribution of institutional jurisdictions and provides a framework for identifying and evaluating alternatives.

An instructive example of the workings of comparative institutional analysis is the case of long latency diseases, whose original cause is difficult to determine many years later. Workers' compensation has been successful in many areas because its test for compensation and liability-whether the injury occurred "on the job"-is simple and generally relies on easily discernible facts; but it has been quite ineffective in the context of long latency occupational illnesses that could have been caused by many factors, only some of them job-related. This experience suggests that the workers' compensation model will be inappropriate in other contexts, such as general environmental pollution, that involve illnesses whose causes are similarly difficult to establish. Accordingly, administrative compensation schemes for environmental illnesses are likely to encounter severe problems. If so, risks of illness from environmental exposures should probably be dealt with by other means, such as a combination of regulation and governmental and first-party insurance. The experience with workers' compensation also suggests that a system of no-fault liability and compensation for medical injuries will prove feasible only if one can readily tell which illnesses were caused by the types of mishaps in medical procedure that give rise to liability.

Another entry point for comparative analysis of injury contexts and institutions is the activity of victims, including variations in the extent to which victim conduct contributes to the risk of injury, in victim knowledge of risk, and in the extent of enterprise control over the activity of potential victims. For example, when a victim's conduct contributes substantially to the risk of injury, efforts to reduce such risk by regulating only the conduct of enterprises may be difficult, costly, and of limited effectiveness, as the checkered performance of OSHA, automobile, and consumer product regulation indicates. A corollary of this fact is that victims must have appropriate incentives to take care. While self-preservation provides some incentive, the additional incentive that the le- 
gal system traditionally has provided-denial of compensation because of contributory negligence-may be significant in securing appropriate reductions in risk. In the hospital and environmental contexts, by contrast, whether the victim exercises care is less important, and attention should focus on improving incentives, regulatory or otherwise, for enterprises to behave with care.

By ruling out employee fault as a bar to recovery, workers' compensation systems reduce victims' incentives to take care. This does not create significant problems in the workplace, however. First, workers' compensation does not cover noneconomic losses and often provides only partial compensation for economic loss. This co-insurance feature gives workers incentives to take care. Second, employers exercise close, ongoing control over the conduct of workers, the potential victims. Employers have strong incentives to manage workplace practices so as to reduce workers' contribution to risk. The riskier the job, the more an employer must pay for workers' compensation liability insurance, and the higher the wage he must offer to attract workers. Third, employers can be selective in hiring and can weed out applicants likely to be careless.

These features are missing, however, in the consumer products area. The law provides full compensation, and it is generally not feasible for enterprises to weed out careless consumers or control their conduct. This suggests either that contributory or comparative negligence should be restored, or that contractual arrangements should be allowed to operate in order to give consumers incentives to exercise care (for example, by limiting the compensation provided and thus introducing a form of co-insurance). The contractual solution seems especially appropriate here, since a contractual relation often already exists between the enterprise and potential victims.

These contractual arrangements will work effectively, of course, only if potential victims have adequate information about risk. Government may have to ensure that such information is available, either by providing the information itself or requiring manufacturers to do so. When this is not feasible because the information is too complex or extensive, government may have to take decisions away from consumers, either by giving the decisions to better-informed agents (such as physicians in the case of prescription drugs) or by imposing product regulation, however clumsy.

The foregoing evaluations have been entirely qualitative. In undertaking a comparative institutional analysis, however, it may be possible to quantify certain aspects of institutional perform- 
ance. For existing compensation systems such as social security, workers' compensation, first-party insurance, and tort litigation, one could gather and analyze data concerning their relative importance in providing compensation for different injuries as well as their relative administrative costs. Administrative costs-which are particularly high in the tort system-become more important as the injuries involved become less severe; at some point, administrative costs may overwhelm compensation. Other aspects of institutional performance-in particular, the incentives provided for risk reduction-will, however, be far more difficult to quantify. Here comparative analysis must remain largely qualitative in nature.

Whether there is a "crisis" in tort law is ultimately a relative question, to be answered by determining whether there are institutional alternatives that can better meet tort goals without excessive administrative costs, overdeterrence, or insurability problems. One possible outcome of these assessments is the total elimination of tort law. For example, tort law's functions of compensation and insurance might be reassigned to governmental and first-party insurance schemes, its incentive function to regulation, and its condemnatory function to the criminal law. But such a step would require improbable political consensus and is also unlikely to be justified by considerations of social welfare.

For all its faults, tort law has several important advantages over other institutions. A comparative analysis of institutional productivity must avoid the tendency to denigrate an inevitably imperfect status quo in contrast to idealized alternatives. With respect to incentives, for example, tort has a number of distinct advantages over alternatives such as command and control regulation. Tort remedies are initiated by victims, who may often know more about the existence and circumstances of injury than do government officials. In addition, tort's incentive effects are pervasive, whereas regulation is context-specific and requires considerable political and administrative mobilization. Finally, tort affords firms complete flexibility in responding to the prospect of liability, whereas command and control regulation is often rigid, imposes disproportionate burdens on new products and processes, and is vulnerable to exploitation by interest groups.

Nonetheless, comparative institutional analysis may recommend significant changes in the existing allocation of jurisdictions among institutions that would have the effect of significantly diminishing tort's role. As I have already noted, the workers' compensation model might be extended to medical malpractice, and contractual arrangements might to a significant extent displace the 
existing system of products and service liability. The need for tort liability incentives might decrease significantly if regulation began to rely on expanded use of economic incentives or even private enforcement.

Finally, the case for tort as a residual system of compensation would be greatly weakened if gaps were filled within existing systems of public and private medical and disability insurance. Many European nations have greatly reduced the role of tort by adopting more comprehensive social insurance programs and no-fault liability schemes for particular areas such as automobile and drug injuries. New Zealand, to offer another example, has adopted comprehensive social insurance for accidental injuries and has virtually abolished tort liability for such injuries.

\section{IV.}

My analysis thus far has accepted the social welfare reorientation of tort goals and has suggested a comparative analysis of different institutions to identify better means for achieving those goals. As mentioned earlier, an alternative response is to reject this reorientation and affirm that tort law is and should continue to be founded on principles of corrective justice. But the institutional implications of this second response ultimately may not be very different than those of the first, because contractual and quasi-contractual alternatives to tort law are available and because utilitarian constraints on securing corrective justice through traditional tort litigation make these alternatives attractive.

In the occupational and consumer context, the enterprise and potential victims have a direct or indirect contractual relationship. This relationship permits tort liability to be displaced by agreements on compensation for injury. As Richard Epstein has pointed out, a statutory system of no-fault liability on the model of workers' compensation can be understood as the collective adoption of a standard form of compensation agreement similar to that which the parties would adopt by contract. The standard form reduces the transaction costs that would result from each individual contracting separately.

In the environmental context, the enterprise and potential victims are strangers to one another and contract is not feasible. In this context, however, tort liability is unlikely to be effective in protecting or compensating victims because of causal uncertainties, high administrative costs, and the relatively low levels of risk per individual, which may mean no individual will find it worthwhile to sue. In these circumstances, regulation will be necessary to pro- 
vide effective protection for personal rights, and social insurance may be needed to compensate loss. Wholesale tort law remedies of the "public law" variety are another possible response to these practical constraints on achieving corrective justice through traditional tort litigation in the context of enterprise personal injury.

V.

The analysis thus far has sidestepped some fundamental questions raised by the current debate over tort law: what are the appropriate overall levels of compensation and incentive for enterprise personal injuries? How far should we seek to reduce the risk of personal injury, bearing in mind that the costs of doing so, including deterrence of socially useful activity and innovation? How generously should the injured be compensated?

The doctrinal crisis in tort law and the legislation proposed or adopted in response have been triggered in large part by the growing perception that excessive and unpredictable tort liability has resulted in serious overdeterrence, harmed the United States in industrial competition with other nations where tort liability plays only a minor role, and created enormous administrative costs. Many who hold that tort law is experiencing a systemic crisis have similar concerns.

Others, however, take a diametrically opposed position. They assert that existing levels of liability and compensation are by no means excessive and are in some areas seriously inadequate. For example, they widely decry the failure of tort law to provide adequate remedies for health risks generated by pollution and toxic substances. Some would cure this deficiency by relaxing doctrinal barriers to tort recovery, including traditional requirements with respect to proof of causation. Others favor development of institutional alternatives to private tort litigation, including administrative compensation schemes or a new "public law" system of tort liability. The apparent failure of the tort system to reach many cases of medical malpractice also has generated proposals for alternatives that would provide compensation to more victims.

Are we imposing too much liability or too little? While the appropriate answer surely will depend on the specific context of injury, comparative institutional analysis seems unlikely to provide much help in finding it. But comparative analysis may help us determine whether and in what circumstances it is worth bearing the high costs of the private tort litigation system in order to achieve the incentive and compensation goals that we choose. Institutional realignments may enable us simultaneously to achieve those goals 
more fully and to reduce the costs of doing so. For example, workers' compensation has been largely successful in providing prompt compensation for workplace accidents and safety incentives (at least for larger employers whose insurance premiums are experience-rated) while reducing administrative costs and insurability problems.

Workers' compensation and products and malpractice liability both increased sharply during the 1970s. But because the standards and amounts of liability are far more predictable in workers' compensation, adequate and affordable insurance has remained available. Administrative costs are also far lower in workers' compensation than in the tort system because the standards of liability and compensation are simplified and because punitive damages and damages for pain and suffering are unavailable, greatly reducing litigation. A shift (whether through contract or statute) from tort liability toward a workers' compensation model for products or malpractice injuries thus could promise significant alleviation of problems that have excited concern-although such a shift would have to confront the problems, noted above, of providing proper incentives to victims and resolving causation issues.

In the end, of course, we cannot escape the question of how safe or how generous a society we should strive to be, or what conduct should be condemned as socially irresponsible. These choices are not technocratic ones. But even here, the performance of various institutions is relevant. The different institutional systems of compensation, incentive, and sanction are not mere instruments for realizing objectives that are exogenously fixed. Decisions about levels of compensation and incentives, and about standards for sanctioning, are made in large part through the institutions that we select to realize our objectives. Different institutions make these decisions through different processes-through adjudication by judges and juries, through contract and collective bargaining, through rule making by regulators, or through legislation by politicians. The processes by which decisions are reached inevitably affect the decisions themselves.

Institutional analysis can educate us about the decisional characteristics and tendencies of these different institutional processes. For example, we can compare the levels of compensation and the administrative cost-effectiveness of different institutional systems. Incentive effects, as already noted, are notoriously more difficult to measure. But we can calibrate and compare one aspect of incentives by identifying differences in the imputed value of life or injury in jury and workers' compensation awards, risk-compen- 
sating wage differentials, and regulatory standard setting. We can also examine how well various institutions obtain and use information on the social costs and benefits associated with enterprise activities in setting incentives.

Such information and analysis only can serve as a guide: it will rarely single out a given institution as "best" in a given injury context. We likely will continue to rely on a combination of institutions. In part this tendency toward institutional overlap may reflect the desirability of hedging our bets in the face of continuing ignorance about important features of institutional performance, as well as political obstacles to more far-reaching change. But there are more affirmative justifications for institutional pluralism. Redundancy, competition, or partial division of labor among several institutions may produce better performance over the long run than reliance on any single institution.

The tort system has important strengths as a process of social decision. It allows for mobilization of private energies to identify and deal with problems that have not been adequately addressed by other institutions. It frees individuals from total dependence on collective bureaucratic remedies and gives them a personal role and stake in the administration of justice. It provides a back-up guarantee of redress. In a society such as ours, these are important virtues. But it may be possible to build some of these features into other institutions as well. We must also give due regard to the tort system's comparative performance in providing appropriate incentives, delivering cost-effective compensation, and imposing fit sanctions. Each of these considerations must be weighed in deciding whether the tort system should be modified and its jurisdiction altered. It is in these terms that the question of crisis in tort law must be ultimately addressed.

Insofar as change is sought through the legislative process, comparative institutional analysis will play an admittedly limited but nonetheless potentially important role. The legislative response to date has been framed by a doctrinal view of the tort law crisis, but more systemic consideration and change remains an open possibility. The response of the judiciary is very much in flux. Courts may well continue the extension of enterprise liability in tort into new fields, such as environmental pollution. If so, they are likely to mobilize even stronger pressures for legislative intervention. Judges who are wary of this prospect and who adopt a doctrinal view of the tort crisis will be far more cautious and may abandon or limit recent innovations that have expanded tort liability. The systemic view implies a judicial willingness to allow the pre- 
sent tort litigation system to be selectively displaced, not only by statutory systems but also through resuscitation of contract. It would be folly to suppose that the current symptoms of crisis intimate the eventual death of tort. But the recent advances of tort have exposed weaknesses in the foundations that may presage large-scale institutional restructuring. 